\title{
Origins of Eponymous Orthopaedic Equipment
}

\author{
Clifton Meals BA, Jeffrey Wang MD
}

Received: 2 April 2009/ Accepted: 22 December 2009/Published online: 13 January 2010

(C) The Author(s) 2010. This article is published with open access at Springerlink.com

\begin{abstract}
Background Orthopaedists make great use of eponymous equipment, however the origins of these tools are unknown to many users. This history enriches, enlightens, and enhances surgical education, and may inspire modern innovation.

Questions/purposes We explored the origins of common and eponymous orthopaedic equipment.

Methods We selected pieces of equipment named for their inventors and in the broadest use by modern orthopaedists. We do not describe specialized orthopaedic implants and instruments owing to the overwhelming number of these devices.

Results The history of this equipment reflects the coevolution of orthopaedics and battlefield medicine. Additionally, these stories evidence the primacy of elegant design and suggest that innovation is often a process of revision and refinement rather than sudden inspiration. Their history exposes surgical innovators as brilliant, lucky, hardworking, and sometimes odd. These stories amuse, enlighten, and may inspire modern orthopaedists to develop creative solutions of their own.

Conclusions The rich history of the field's eponymous instruments informs an ongoing tradition of innovation in orthopaedics.
\end{abstract}

Each author certifies that he has no commercial associations (eg, consultancies, stock ownership, equity interest, patent/licensing arrangements, etc) that might pose a conflict of interest in connection with the submitted article.

C. Meals ( $₫)$, J. Wang

David Geffen School of Medicine, University of California at

Los Angeles, 432 Comstock Avenue, Los Angeles, CA 90024, USA

e-mail: cliftongm@gmail.com

\section{Introduction}

Modern orthopaedic curriculum largely ignores the profession's history; however, looking back has advantages. By studying our predecessors, we honor them, learn to emulate their success, and enhance our ability to pass their knowledge on to students. Examined side by side, their varied personalities represent a study of the creative orthopaedic mind and foster an appreciation of the innovative process. Ultimately, these past innovators may inspire their modern counterparts.

We therefore explore the origins of eponymous equipment in broadest use by modern orthopaedists. We exclude surgical instruments because these have been described, and we exclude all but the most classic orthopaedic implants owing to the overwhelming number of these devices [24, 32].

The eponyms orthopaedists use daily belong to extraordinary individuals, among them soldiers, laypersons, a grave robber, and a Wild West vigilante.

\section{Bandages, Slings, and Splints}

Henry Austin Martin (1824-1884)

\section{Martin Bandage}

Henry Martin was the first to use a wide, rubber, roller bandage to treat vascular ulcers [56] (Fig. 1).

$\mathrm{He}$ was proud of his invention and insisted that it be used exactly as he described [30]. "Proud and imperious by nature, and often impatient in temper, [Martin] brooked no personal affront, and knew no fear of personal 


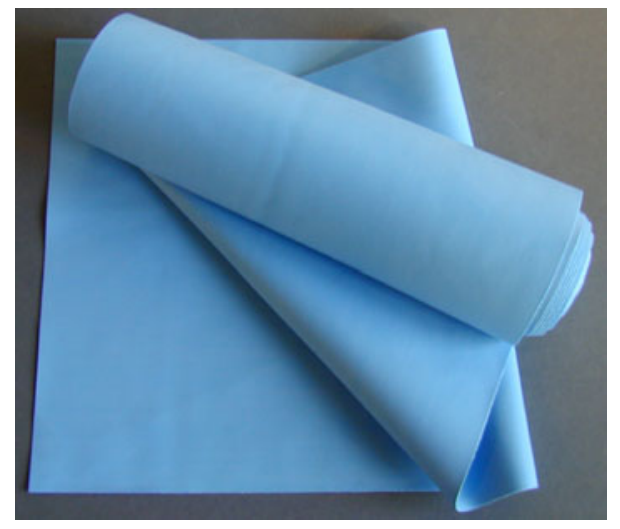

Fig. 1 A Martin bandage is shown. This bandage often is referred to as an Esmarch.

consequences in his bold and vigorous attacks on opponents. His knowledge of the old medical and surgical writers was very great, and his memory so retentive that it was easy for him to quote their views and statements in support of his positions" [41].

Today, although varicose ulcers are treated with compression stockings rather than a rubber wrap, Martin's bandage is used routinely, in the manner of Esmarch's bandage (see below), to exsanguinate and tourniquet an extremity. Martin's bandage either is tied on itself, or a pneumatic tourniquet is used in place of the strap built into Esmarch's bandage.

Martin is also notable for introducing animal vaccination to the United States [56].

\section{Johann Friedrich August Von Esmarch (1823-1908)}

\section{Esmarch Bandage/Tourniquet}

Esmarch, Surgeon General to the German army, was well acquainted with battlefield injuries (Fig. 2). Challenged by blood loss and limb-threatening trauma, he designed a twocomponent device consisting of a bandage and an attached strap that could sequentially exsanguinate and tourniquet an arm or leg [38]. Today, Martin's rubber bandage is used for this purpose because it is easily tucked beneath itself to create a tourniquet. Used in this fashion, Martin's bandage often is referred to by orthopaedists as an "Esmarch." The incorrect spelling, "Esmark," is also common.

Esmarch was known as a conservative surgeon who favored limb reconstruction to amputation. A pioneer of disaster triage, Esmarch prioritized soldiers for whom he could do the most good rather than simply treating officers first [5]. So that soldiers could treat themselves, Esmarch designed a triangular bandage printed with instructions for its use, part of a prototypical first aid kit [5, 38] (Fig. 3).

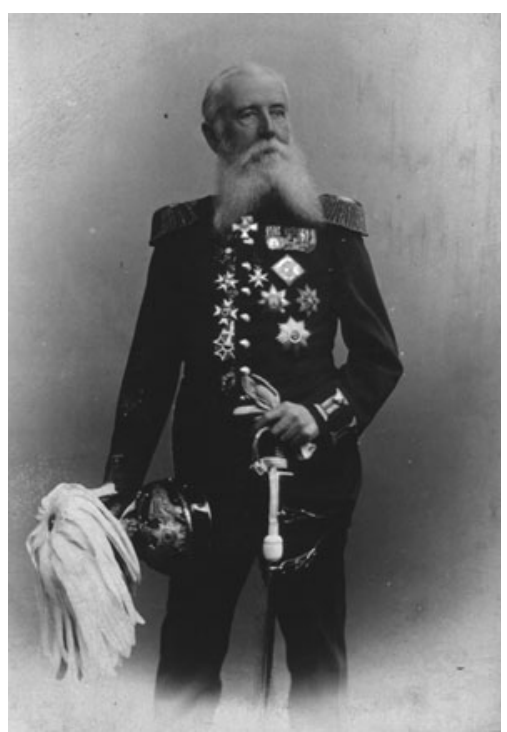

Fig. 2 Johann Friedrich August Von Esmarch is shown. (Photograph reprinted courtesy of the National Library of Medicine.)

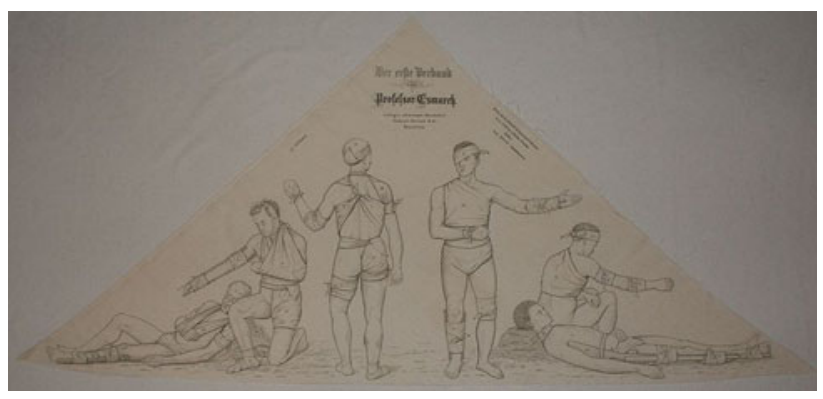

Fig. 3 Esmarch's triangular bandage with diagrammatic instructions for use is shown. (Photograph reprinted courtesy of Wikipedia.)

For a man concerned with the welfare of the common soldier, Esmarch took a harsh attitude toward students, notoriously granting no grade higher than a B in his academic career [5]. Accused of this and of being a weak public speaker, Esmarch was prohibited from lecturing more than 1 hour a semester and was then denied any speaking time at all. His ineptitude as a teacher may have stemmed from early discomfort in the classroom: one biographer describes young Esmarch as "sincerely and repeatedly [trying] to provoke his own expulsion" [38].

Hugh Owen Thomas (1834-1891)

\section{Thomas Splint}

The "Father of British Orthopaedics," was descended from a family of bone-setters, and Thomas learned this trade from his father (Fig. 4). The elder Thomas made his living 


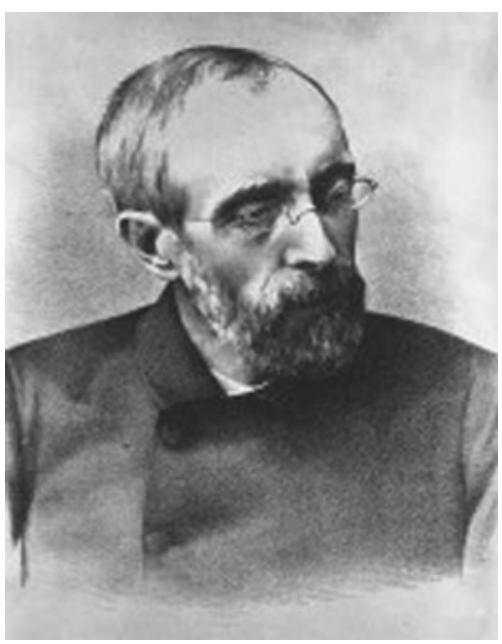

Fig. 4 Hugh Own Thomas is shown. (Photograph reprinted courtesy of the National Library of Medicine.)

among dockworkers and seamen, working people prone to orthopaedic injury. Wary of academic disdain for his craft, and so that his sons might avoid being sued, Evan Thomas insisted that Hugh receive formal medical education. Hugh Thomas was educated in Edinburgh, London, and Paris before rejoining his father and eventually setting out on his own.

Thomas's splint was braced against the pelvis so traction applied to the leg was not dissipated in distraction of the hip. His splint likely evolved from Thomas' interest in treating tuberculous lesions of the knee (Fig. 5). However, it was World War I and the successful use of his splint to stabilize compound battlefield fractures that made the device famous [25, 54]. The Thomas splint dramatically reduced mortality in the aftermath of open, combat-related fractures [54]. The splints were manufactured in Thomas' workshop, presumably the same place where Thomas designed a collar for stabilizing the cervical spine, an osteoclast, and a wrench for reduction of broken bones. (Thomas may have used a similar wrench for manipulation of congenital clubfeet.)

Thomas never gained an official hospital appointment, choosing instead to work out of a private care facility [25, 54]. It has been suggested that Thomas had difficulty working with his peers, and that what a biographer calls the doctor's "peculiar temperament" [54] made praise for his accomplishments slow to surface. In addition to his distinctive personality, Thomas was known for his raked sailor hat, ever-present cigarette, and three-part dogma of recuperation, "enforced, uninterrupted, and prolonged rest," which is said to have influenced British surgeons for a century. Thomas rested little. Although Sunday was designated his "free" day, this meant that on Sunday, patients were treated free of charge $[25,54]$.
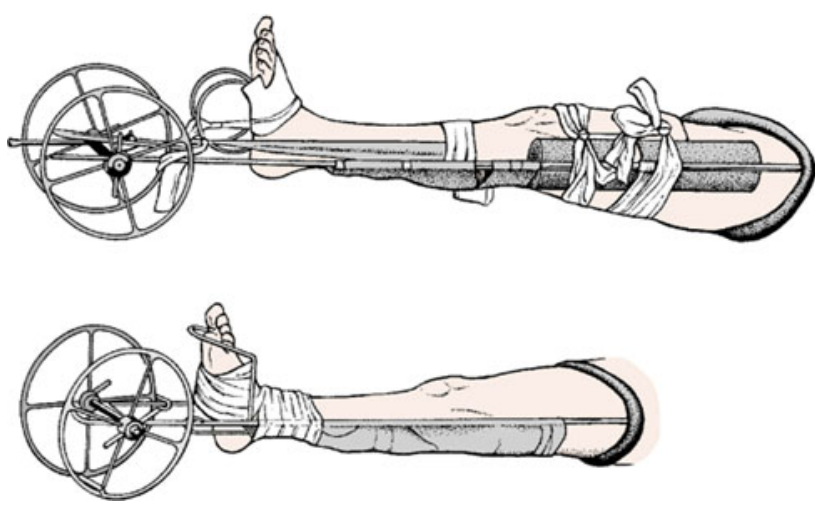

Fig. 5 Early Thomas Splints are shown. (Published with permission from Elsevier. This figure was published in Browner B, Levine A, Jupiter J, Trafton P, Krettek C. Skeletal Trauma: Basic Science, Management, and Reconstruction. Ed. 4. Philadelphia, PA: Saunders; Copyright Elsevier 2008.)

Paul Gerson Unna (1850-1929)

\section{Unna Boot}

Paul Gerson Unna was a German dermatologist (Fig. 6). $\mathrm{He}$ found that plasters manufactured by Johnson and Johnson were inherently acidic and therefore irritating to the skin. Unna used zinc oxide to neutralize the plaster's noxious effect. Unna's eponymous bandage material contains zinc oxide, glycerin, and gelatin. It prevents itching and does not break down skin. Fashioned into a boot, Unna's bandage is used to treat ulcers of the leg and to promote healing of skin grafts. Orthopaedists use Unna boots to support the ankle postoperatively and encourage closure of incisions.

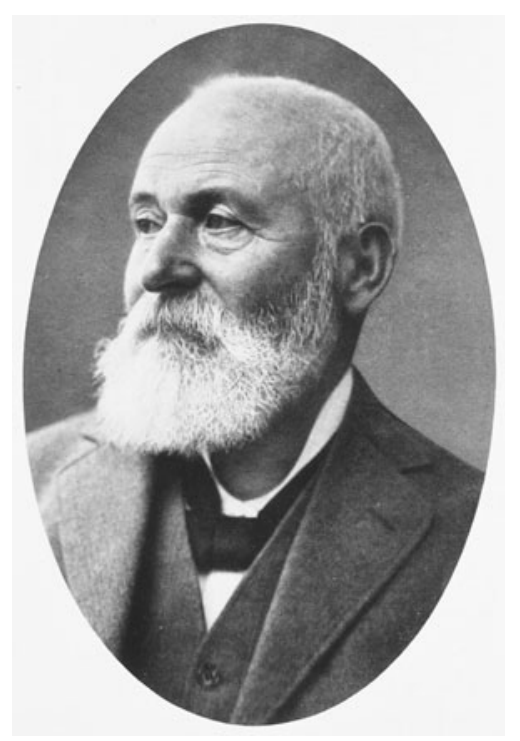

Fig. 6 Paul Gerson Unna is shown. (Photograph reprinted courtesy of the National Library of Medicine.) 
Unna was a master of dermatology and a prolific inventor. He produced a single-author, 1200-page volume on skin diseases, Histopathologie der Hautkrankheiten [Histopathology of the Diseases of the Skin] [48], and founded the first dermatologic journal, Monatshefte fur praktische dermatologie, renamed Dermatogische Wochenschrift. Unna described several cell types, and published pioneering work on histochemical stains. He helped bring to market various moisturizing creams, the first commercially available toothpaste, and the first adhesive tape.

Unna owed his varied achievements to long and odd hours. He awoke routinely at 2:00 AM to work for 2 hours before returning to bed, and in daylight hours, divided time between patients, the laboratory, and his cello [22]. He is described as a pompous man who rarely smiled, although his countenance may have belied a certain generosity [55]. Unna donated the military pension he received to award achievement in dermatology [22].

\section{Alfred Velpeau (1795-1867)}

\section{Velpeau Sling}

This French surgeon is remembered for his sling, featuring a sleeve for the forearm and a strap passed behind the neck, although his name additionally denotes a type of hernia, an anatomic canal, and a deformity (Fig. 7).

As a child, Velpeau attempted to treat a young friend he believed to be depressed [14]. The concoction Velpeau prepared, however, made his patient ill. When the town's physician was called, the precocious Velpeau impressed

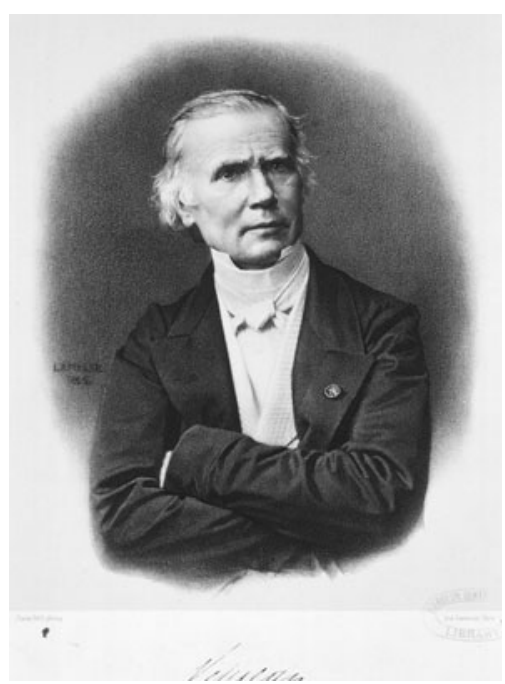

Fig. 7 Alfred Velpeau is shown. (Photograph reprinted courtesy of the National Library of Medicine.) the doctor despite the boy's recent pharmacologic misadventure. The physician introduced Velpeau to a local nobleman, and this aristocrat asked Velpeau to sit with his own children for tutoring. Thus began Velpeau's formal education.

Body snatching was part of Velpeau's later studies. In the student's own words: "Here we are every night at 2:00 am with ladders, climbing walls as criminals. This way we obtained 36 necropsies in a few months. People guessed about our profanities and twice I was fired on by inhabitants. I still have some lead in certain places" [14].

\section{Anesthesia}

August Bier (1861-1949)

\section{Bier Block with Esmarch Bandage}

August Bier, a German surgeon, developed spinal anesthesia and subsequently the extremity-specific anesthetic technique that bears his name [16] (Fig. 8). Bier feared the general anesthesia available in his time because the postoperative vomiting it produced could tear intestinal sutures. Likely inspired by his association with Heinrich Quincke, who routinely performed lumbar punctures, Bier believed directed anesthesia could be achieved by injecting anesthetic into the immediate vicinity of the spinal cord, in his words, by "[bringing] cocaine next to the nerves." This was tested first on Bier himself, in whom the technique was unsuccessful, and then on Bier's colleague. Bier's partner became insensate to hammer strikes about the legs, the

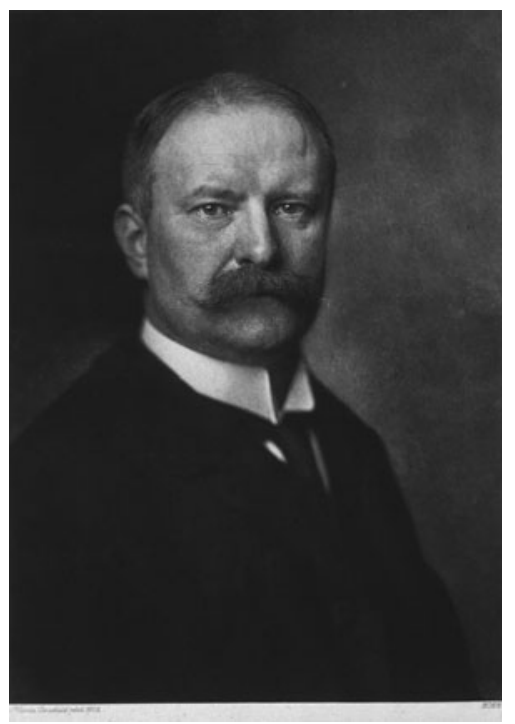

Fig. 8 August Bier is shown. (Photograph reprinted courtesy of the National Library of Medicine.) 
application of a lit cigar, and firm pressure on the testicles. Bier and his partner had headaches for a week, sufficient to keep them away from work [16, 49].

Bier was the protégé of Friedrich Von Esmarch, and Esmarch's rubber bandage/tourniquet played a central role in the development of Bier's self-named technique. To the consternation of his contemporaries, Bier was an outspoken advocate of homeopathy, and his interest in alternative medicine was manifest with his auto-experimentation with Esmarch's tourniquet [16]. Bier worked for a month with a tourniquet around his arm and at least once slept with a tourniquet around his neck, resulting in headaches and vertigo [50]. Despite these adverse effects, Bier recommended tourniquetting for tuberculosis, elephantiasis, parotitis, eye and ear illnesses, joint inflammation, and other conditions [49].

Pursuing an interest in directed anesthesia and familiar with tourniquets, Bier discovered that an extremity could be exsanguinated with Esmarch's bandage and that subsequent venous administration of procaine produced effective and quickly reversible anesthesia $[6,50]$. Bier's block, however, was not problem-free. In the original description of his technique, Bier addresses the potential for procaine poisoning and reports that one patient vomited and collapsed when the tourniquet was released [6, 21]. In 1965, Kennedy et al. [23] reported arrhythmias, syncope, and one episode of cardiac arrest while performing Bier's block with lignocaine, prompting the authors to discontinue their use of this drug. Prilocaine was determined, in the 1960s, to have fewer systemic side effects and contributed to a resurgence of Bier's technique [16, 21].

\section{Drains, Lines, and Catheters}

Frederic Eugene Basil Foley (1891-1966)

\section{Foley Catheter}

Frederic Foley did not invent the urinary catheter, which had been used since antiquity [33], nor was he the first to experiment with balloon-tipped drains. However, he did improve on existing designs, creating an integrated tool and coating it with latex. Foley may have been more interested in affecting hemostasis after prostate surgery than in routine urinary drainage, although his design is well adapted to both uses [57].

A friend of Foley's described the inventor as having a "great presence and egocentricity" and speaking in an "irascible and commanding voice" [34]. Perhaps it was strength of personality that earned Foley his job as a St Paul staff urologist, a position for which he had no specialized training. It is rumored that Foley's interviewer at the Ancker/Ramsey County, now Regions Hospital, misheard Foley, and knowing that Foley had worked with Cushing, accepted the applicant as a neurologist [17, 34]. Cushing, in fact, had dissuaded Foley from entering neurosurgery [17].

Foley had a sense of humor to match his outspoken personality. His parties featured a tuxedo-clad mannequin, "Mr. Freely," that dispensed scotch from the penis [34].

\section{Otto Luer or Wulfing Luer}

\section{Luer Lok/Luer Slip}

The German Otto Luer recognized in the 1880s that a $6 \%$ taper applied to a stopper and its corresponding bottle allowed for a secure but impermanent fit. Approximately 50 years later, Fairleigh S. Dickinson, cofounder of Becton Dickinson, patented the Luer Lok fitting, capitalizing on Luer's taper [29] (Fig. 9).

The eponym also may be traceable to the name Wulfing Luer, given to a medical instrument company. Wulfing Luer may be a person's name or the amalgamated name of the company, either challenging the attribution to Otto Luer or supporting it [47].

\section{Charles Bingham Penrose (1862-1925)}

\section{Penrose Drain}

Charles Penrose said, "when in doubt, drain" [37] (Fig. 10). Penrose was determined that recovery from abdominal surgery become "habitual rather than occasional," and he sought to quell the fear his colleagues had of abdominal drains [1,37]. This was a well-founded fear given that gauze wicks in use at the time would adhere to healing tissue and become difficult to remove. In Penrose's

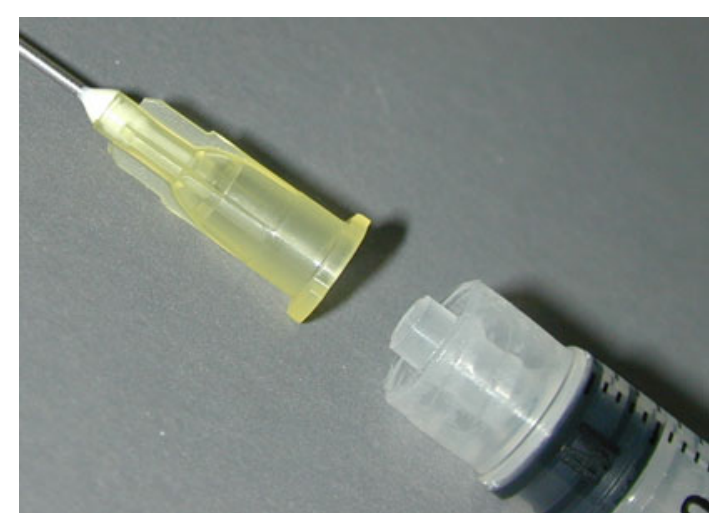

Fig. 9 A Luer Lok is shown. 


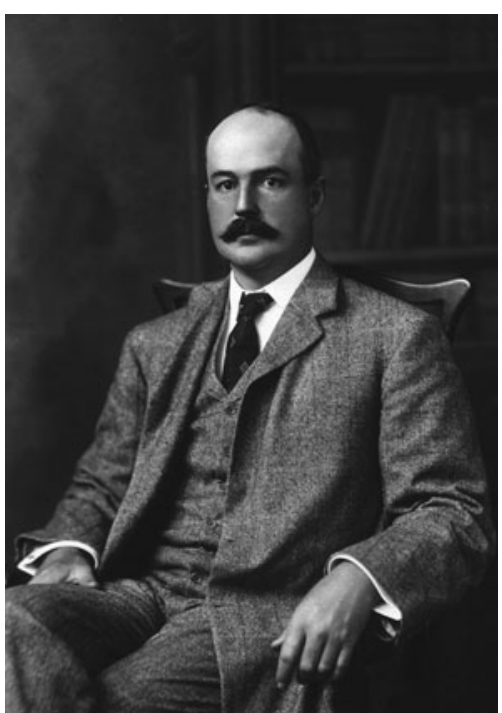

Fig. 10 Charles Bingham Penrose is shown. (Photograph reprinted courtesy of the National Library of Medicine.)

words, "the surgeon fears to use too much force in attempts at withdrawal...To avoid this difficulty, [I] had for some time employed a drain made by surrounding the gauzebag with an ordinary rubber condom, the end of which has been cut open" [1].

Penrose's victory over this important surgical problem is perhaps not surprising from a man who survived a bear attack, swam 15 miles through the ocean on a dare, overcame tuberculosis, and escaped a lynch mob [31, 37]. The last two of these feats took place in Wyoming, where Penrose had traveled to recuperate from consumptive symptoms. In Cheyenne, he appealed to the city engineer who permitted Penrose to refill, over the course of weeks and for the sake of the doctor's health, a municipal drainage ditch. It was during this time that Penrose joined a group of ranchers on the trail of a pair of cattle thieves. When the thieves were tracked down and killed, the local citizenry jailed the vigilantes and threatened to hang them. Penrose eventually was released without further incident [31].

Penrose graduated from the University of Pennsylvania Medical School and earned a PhD in physics from Harvard. $\mathrm{He}$ is described as brusque, befitting his adventures in the Wild West. A biographer states, "when an admiring lady patient remarked on the birth of his son, 'aren't you thrilled on the coming of Little Boy Blue?' he supposedly answered, 'He is not a blue baby; I am not thrilled, but of course, the young of all vertebrates are interesting" [37].

In some instances, Penrose drains have been replaced by the Jackson-Pratt closed drainage system. However, we have been unable to identify those responsible for this popular suction drain.

\section{Traction and Reduction}

Fritz Steinmann (1872-1932)

\section{Steinmann Pin}

Fritz Steinmann was a committed student of Theodore Kocher, another famous Swiss surgeon. When asked about his free time under Kocher, Steinmann replied that "not only did he not have one moment of free time, but that he often went months without leaving the hospital grounds."

Early in his professional career, Steinmann practiced out of his apartment, where he allowed patients to recover postoperatively under the care of his wife. Later, Steinmann helped build a private hospital. An early xray machine was installed, allowing Steinmann to quickly evaluate trauma.

Steinmann's interest in trauma was evident in his study of gunshot wounds. The curious doctor hung skeletons from a tree near his home, shot at them himself, and examined the effects [40].

Steinmann first described his skeletal traction technique in 1908 [43]. The pin Steinmann advocated was simple, 3 to $5 \mathrm{~mm}$ in diameter, sharpened to a point, and designed for use with a hand drill. Tongs then were applied to the pin ends, and traction was achieved by hanging weights fixed to the tongs with sturdy cord. Steinmann knew his technique held several advantages over plaster casting, namely, freedom in positioning of patients' limbs and the potential to adjust distracting force. Steinmann was wary, however, of infection. He insisted on asepsis and suggested that, although mechanically inferior, the use of two unicortical pins might obviate drawing of an exposed bicortical pinend through bone on removal [40,44]. Steinmann's idea is used widely today, especially for preoperative treatment of trauma, as it is easily accomplished, allows for swelling, permits access to the injured site, and avoids dermal breakdown associated with skin traction.

Steinmann was committed to a public argument regarding the priority of his traction apparatus [40]. Italian orthopaedist Alessandro Codivilla had described a similar means of applying traction in 1903 [8] and 1904 [9]. In 1910, Codivilla publicly accused Steinmann of stealing his idea [10]. An impolite dialogue ensued between the two, and a series of rebuttals were published in a popular journal of the time [40].

Martin Kirschner (1879-1942)

\section{Kirschner Wire}

Martin Kirschner, German professor of surgery at Heidelberg, built on the skeletal traction techniques introduced by 
Steinmann [43] and Codivilla [8, 9], without entering their argument over priority [26]. Kirschner preferred, ultimately, to create skeletal traction with thinner hardware, reasoning that chromed $0.7-\mathrm{mm}$ steel piano was less traumatic than Steinmann's pin and reduced the risk of infection. Accordingly, he referred to his modification as "wire extension," rather than "nail extension," the phrase used by Steinmann [28, 39, 44].

Kirschner's thinner wire had a tendency to bend while being inserted and when pulled on, deficiencies Kirschner overcame with a drilling aid and a traction bow of his invention [28, 39].

Although originally used to apply skeletal traction, the Kirschner wire now is used widely to fix fractures, guide cannulated hardware, transfix finger joints, and for tension band wiring of the olecranon and patella [20]. The term Kirschner wire, or K-wire, generally is applied when thinner, flexible pins are used. Although skeletal traction today is accomplished using thin and relatively rigid steel pins, hardware used in this manner popularly evokes the name Steinmann.

Kirschner was a true general surgeon who wrote on a wide variety of subjects [39]. It is of historical note that Kirschner was the first to successfully perform Trendelenburg's pulmonary embolectomy operation, performed emergently and without anesthesia [27, 39, 46].

Kirschner was eulogized as a Tatenmensch (man of action), a title befitting a man of wide surgical ability and the inventor of a supremely elegant and widely adapted surgical solution [20].

\section{Stands, Tables, and Beds}

William W. Mayo (1819-1911), William J. Mayo

(1861-1939), Charles H. Mayo (1865-1939)

\section{Mayo Stand}

The Mayo stand is symbolic of the Mayo tradition in that it was developed for the sake of the student (Figs. 11, 12). As operative onlookers crowded William and Charles' surgical suites, mirrors were installed on the ceilings, and onelegged, mobile instrument stands were designed to best accommodate a surgical arena in which floor space was tight [19].

The Mayo family established one of the early US graduate medical training programs. Charles Mayo claimed that a "concept of interlocking talents and a mood of sharing" was responsible for his institution's success [4].

It is difficult to specifically attribute the instrument stand to an individual Mayo. The brothers shared equitably in their accomplishments. A friend of the Mayos said, "I

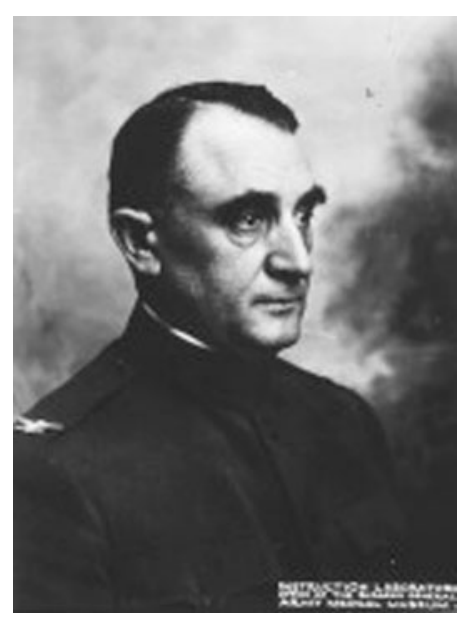

Fig. 11 Charles Mayo is shown. (Photograph reprinted courtesy of the National Library of Medicine.)

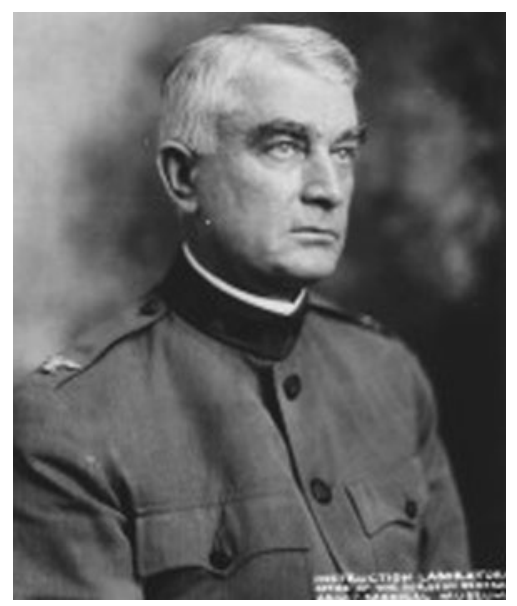

Fig. 12 William J. Mayo is shown. (Photograph reprinted courtesy of the National Library of Medicine.)

believe if Dr Will were elected president of the United States he would accept the office in the name of his brother and himself" [7].

\section{Sir Goldsworthy Gurney (1793-1875) or}

J. Theodore Gurney

\section{Gurney}

Either of two men may be responsible for this eponym. Sir Goldsworthy Gurney was an English surgeon and prolific inventor. He designed a steam-powered car that was used to shuttle paying passengers between English towns (Fig. 13). It is conceivable that his conveyance and his medical background encouraged association between his name and the rolling hospital bed $[12,18]$. 


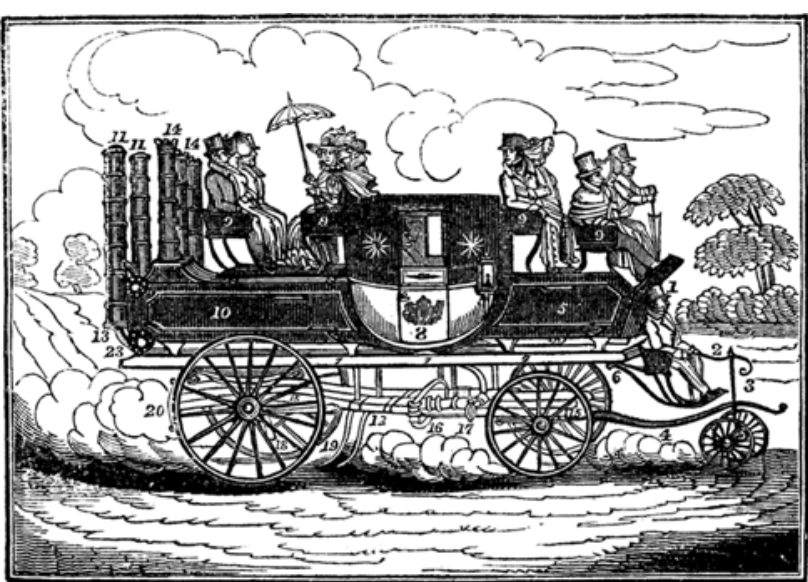

Fig. 13 A Goldsworthy Gurney steam carriage is shown. (Image reproduced courtesy of Wikipedia.)

J. Theodore Gurney was an American inventor who designed a horse-drawn carriage popular in the late 19th century. Observers would have been inclined to make the connection between Theodore Gurney's carriage and the ubiquitous piece of medical equipment that shares his name [18].

Accepting either attribution (or both), this remains an eponym of association. Neither the Englishman nor the American is likely to have invented an appliance of such obvious and ancient necessity.

Friedrich Trendelenburg (1844-1924)

\section{Trendelenburg Position/Table}

This German surgeon is responsible for numerous eponyms [46], however, the one for which he is most famous does not, strictly speaking, belong to him (Fig. 14). The Trendelenburg position was known in the middle ages as the "head down position" [13]. Trendelenburg repopularized the technique and designed an operative table with shoulder braces to facilitate its use [13]. Before designing this table, Trendelenburg required an assistant to physically support the patient's feet during procedures. In addition to permitting superior access to the bladder and encouraging the intestines to retract, Trendelenburg's position allowed for better lighting of the field, derived, in the day, from exterior windows.

The Trendelenburg position continues to be useful in surgery and allows for safe insertion of central lines. Surgeons also refer to the reverse-Trendelenburg position, which Trendelenburg never specifically described [13, 42].

Of particular importance to orthopaedists, the Trendelenburg gait is observed in patients with weak abductors of the hip.

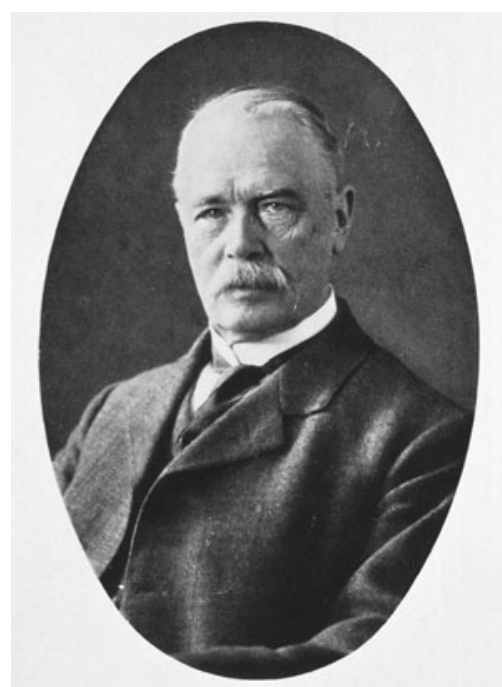

Fig. 14 Friedrich Trendelenburg is shown. (Photograph reprinted courtesy of the National Library of Medicine.)

\section{Vascular}

William Bovie (1882-1958)

\section{Bovie Electrocautery Device}

William Bovie was an assistant professor of biophysics, a field he helped create at Harvard, [2] when he collaborated with Harvey Cushing on the development of a surgical tool that could sever and seal [51]. In Bovie's words, "Dr Cushing attended a staff meeting at the cancer hospital and heard a report of the progress we had made in electrosurgery, and one day soon afterwards he popped his head into my laboratory at Harvard and asked me if I thought we could prevent some loss of blood in a brain operation..." [35].

Bovie was not the first to experiment with the therapeutic application of heat. Four hundred years BC, Hippocrates suggested cautery for the treatment of hemorrhoids: "I recommend seven or eight small pieces of iron to be prepared. You will recognize the hemorrhoids without difficulty for they project on the inside of the gut like dark colored grapes, and when the anus is forced out they spurt blood. When the cautery is applied the patient's head and hands should be held so that he may not stir, but he himself should cry out, for that will make the rectum project the more" [3].

Surgical experimentation with electricity in the early 1900s was born from scientific advances made throughout the preceding century. Edwin Beer and Howard Atwood Kelly, who experimented with sparking devices in the treatment of bladder diseases, were among those investigating the surgical utility of electricity immediately before World War I. Harvey Cushing first used Bovie's 
electrosurgical device to remove a cranial myeloma on October 1, 1926 at the Brigham hospital in Boston [35].

Bovie described himself as a "middle man" who split his time between Cushing's operating room and his own electrical experiments. This allowed him "to learn a little bit of both ends of the problem." Bovie's know-how was invaluable to Cushing who understood little of the physics involved in the new procedure. The famous neurosurgeon likened himself to an adept driver who need not understand the principles of internal combustion [51].

Bovie summarized the unique accomplishment of the two innovators in a letter to Cushing: "The electrosurgical methods which have been used in your operating room differ from other electrosurgical methods in that we have combined into one machine both the coagulating and cutting currents, and by a further modulation of the character of the current, we have controlled the degree to which the cut tissues are coagulated, or more correctly expressed, are dehydrated. I believe that this is of the very greatest importance, in fact it is my opinion that this step alone will put electrical surgery on the map. The machine you have used, is I believe, the only electrical surgical machine having the necessary variety of currents... The progress of electrical surgery has been retarded because manufacturers could not give the surgeon what he needed for they had no way of knowing his problems and the surgeon has not been able to ask the manufacturer for suitable currents because he has not known about the peculiar properties of these high frequency currents... I do feel that we have taken some progressive steps which will not have to be retraced" [51].

Bovie sold the rights to his invention for \$1 [35], likely an act of generosity rather than shortsightedness. Cushing claimed that he and Bovie were more interested in advancement of the field than financial gain [51].

Bovie was a man who evidently garnered great satisfaction from academic pursuits. He studied stenography in Kalamazoo before moving to Albion College, and then to the University of Missouri where he earned a masters degree in Botany and married his student Martha Adams. Bovie moved to Harvard in 1911 to study plant physiology before joining the Harvard Cancer Commission and beginning to lecture in biophysics. After collaborating with Cushing, Bovie left Harvard for Northwestern University and ultimately settled at Colby College in Maine, where he taught social technology [35].

Christian Johann Doppler (1803-1853)

\section{Doppler Device}

Many associate the word "Doppler" with "woosh, woosh, woosh," the sound of blood flow monitored in real time

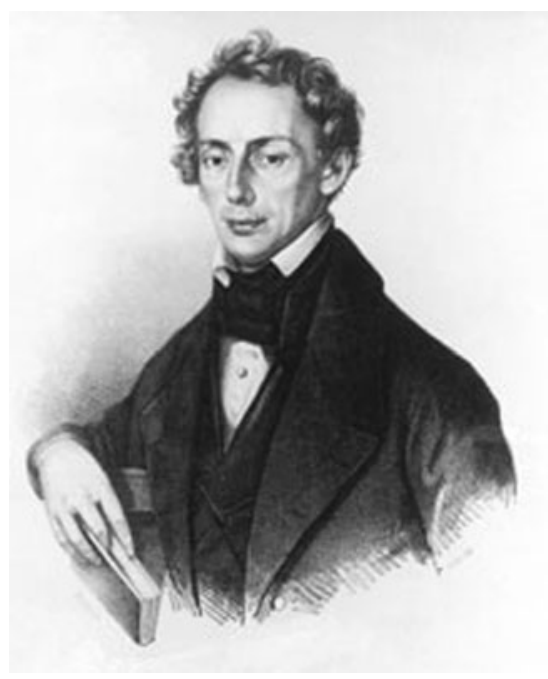

Fig. 15 Christian Johann Doppler is shown. (Image reproduced courtesy of Wikipedia.)

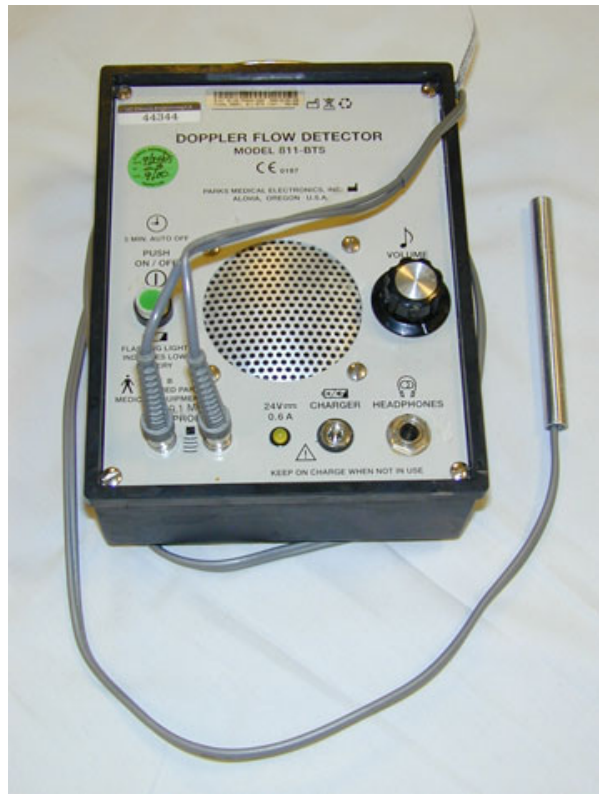

Fig. 16 A modern Doppler device is shown.

(Figs. 15, 16). Austrian physicist Christian Johann Doppler developed the theory on which the eponymous technique relies [15].

Doppler was inspired while watching boats at sea, aware that waves would strike the bow of a ship at a rate dependent on the ship's velocity [15]. If the velocity of a wave's source or observer affected its apparent frequency, Doppler believed he could account for the different colors of some neighboring stars. Doppler's observation on waves was accurate; however, the specific application of this theory to the appearance of stars has been disproved. Nonetheless, modern amendments have made Doppler's theory useful to astronomers $[11,52]$. 
Doppler was nomadic in his academic career and not necessarily popular with students, who claimed he examined them too rigorously $[15,52]$. Doppler also helped to reject Johann Gregor Mendel's application to a European university, a position that the geneticist-monk later won [36].

By using trumpeters aboard a train, it was proved by a Dutch contemporary of Doppler's, meteorologist Christoph Hendrik Diederik Buys Ballot, that sound changes pitch given the velocity of its source [15]. Likewise, sound reflected from moving blood changes pitch as a product of flow.

Doppler's name is everywhere. It denotes the wellknown medical procedure in addition to a type of weather radar, corporations, rock bands, city streets, and a lunar crater [11].

\section{Miscellaneous}

Homer Stryker (1894-1980)

\section{Stryker Saw}

Homer Stryker served in World War I and returned to his native Michigan to study medicine [53]. He chose a career in orthopaedics and, while learning the specialty, began to ponder its challenges. Stryker tinkered with a rubber heel to protect the sole of walking casts and experimented with a rigid frame for turning bed-bound victims with spinal injury $[45,53]$.

Stryker perfected this "turning frame" in his hospital's basement workshop [45]. The Stryker frame was a commercial success and stimulated Stryker to found the Orthopedic Frames Company in 1946 [45, 53]. Stryker paid for this success, however, with an additional year of residency levied against the inventor for spending too much time with his frame and not enough on the wards (Oral communication from Louis Meeks, MD, August 17, 2009).

Stryker invented his eponymous cast cutter in 1945 [53], realizing that a reciprocating saw spared soft tissue that a rotating blade would destroy. Originally powered by a motor from a malted milk mixer, his inspiration affected safe and efficient removal of plaster casts, evolved into various other reciprocating surgical tools, and marked the first in a series of powered medical tools for which the Stryker name is known [45].

Stryker is among the most recognizable corporate eponyms in medicine, and the Stryker family has generously shared in its success. The Stryker Corporation has given millions of dollars to youth groups, the environment, and the arts. The Kalamazoo Kings baseball team plays at the Homer Stryker field, and the University of Michigan hosts two lectureships in the name of its inventive former student [53].

\section{Discussion}

We have reviewed biographic information related to the inventors of eponymous surgical equipment in wide use by modern orthopaedists.

We omitted orthopaedic instruments because these have been described, and we included only the most classic orthopaedic implants owing to the prohibitively large number of these devices. We prioritized what makes these innovators most memorable, and we hope the reader will be inspired to share these stories verbally with students and colleagues.

Our review yields the following noteworthy themes. Many of these inventors performed military service, a product of historical events during the rise of orthopaedics and the fact that combat trauma often involves bones and joints. Many of these men also held academic appointments, indicative of a desire among them to share in their thinking and evidence that innovation often relies on collaboration. With a similar sense of generosity, Stryker, Thomas, and Unna donated time or money to charity, and Bovie declined compensation for his eponymous achievement. An additional theme is evident in that, rather than being truly de novo, many of the inventions described here represent clever enhancements and/or simplifications of preexisting tools. This commonality is testament to the primacy of elegance in orthopaedics, apparent in the design of these most pervasive tools and the specialty's most popular procedures. Finally, it is interesting that certain eponyms, as a product of their evolving popular use, evoke different meanings today than they would have in the inventor's time. Doppler, Esmarch, Gurney and Kirschner are prime examples.

Despite their similarities, these men ultimately were more different than alike. Not all were orthopaedists and not all were physicians. They came from different countries, political environments, and social castes. They had varied abilities, personalities, and fallibilities, suggesting that, other than a desire to create, there is no prerequisite for innovation.

Each operative tool is a lesson in surgical thought. When we examine the history of our most common orthopaedic equipment, we honor a legacy of innovation and may be inspired to add to it ourselves.

Acknowledgments We thank Dr Roy Meals and Susan Meals for their thoughtful advice.

Open Access This article is distributed under the terms of the Creative Commons Attribution Noncommercial License which permits any noncommercial use, distribution, and reproduction in any medium, provided the original author(s) and source are credited. 


\section{References}

1. Abramson DJ. Charles Bingham Penrose and the Penrose drain. Surg Gynecol Obstet. 1976;143:285-286.

2. Achtates F. Dr. William T. Bovie, 1905, biophysicist and inventor: Io Triumphe (Albion College); 1948.

3. Adams F. The genuine works of Hippocrates (translated from the Greek). London, England: London Sydenham Society; 1849.

4. Anya-Prado R, Rubi MG. William and Charles Mayo: their influence on American medicine. J Invest Surg. 2007;20:325-329.

5. Beyer CW, Dick WF. Johann Friedrich August von Esmarch: a pioneer in the field of emergency and disaster medicine. Resuscitation. 2001;50:131-133.

6. Bier A. Ueber einem neuen Weg Localanasthesie an die Gliedmassen zu erzeugen. Arch Klin Chir. 1908;86:1007.

7. Clapesattle H. The Doctors Mayo. Ed 2. Minneapolis, MN: University of Minneapolis Press; 1954.

8. Codivilla A. Sulla correzione delle deformata da frattura del femore. Bull Sci Med Bologna. 1903;3:83.

9. Codivilla A. Zur Behandlung der Coxa vara. Zeit Orthop Chir. 1904;12:91.

10. Codivilla A. Ueber Nagelextension Z Orthop Chir. 1910;27:404.

11. Coman IM. Christian Andreas Doppler: the man and his legacy. Eur J Echocardiogr. 2005;6:7-10.

12. Day L, McNeil I. Biographical Dictionary of the History of Technology. London, England: Taylor and Francis; 1996.

13. Dick WF. The resuscitation greats: Friedrich Trendelenburg (1844-1924). Resuscitation. 2000;45:157-159.

14. Dunn PM. Dr Alfred Velpeau (1795-1867) of Tours: the umbilical cord and birth asphyxia. Arch Dis Child Fetal Neonatal Ed. 2005;90:184-186.

15. Ghori AK, Chung KC. The medical Doppler in hand surgery: its scientific basis, applications, and the history of its namesake, Christian Johann Doppler. J Hand Surg Am. 2007;32:1595-1599.

16. Goerig M, Agarwal K, Schulte am Esch J. The versatile August Bier (1861-1949), father of spinal anesthesia. J Clin Anesth. 2000;12:561-569.

17. Goldblatt D. Such queer moons: Frederic Eugene Basil Foley (1891-1966) Semin Neurol. 1988;8:174-176.

18. Haubrich W. Medical Meanings: A Glossary of Word Origins. Ed 2. Philadelphia, PA: American College of Physicians Press; 2004.

19. History of Surgery at Mayo Clinic. Available at: http://www. mayoclinic.org/surgery/history.html. Accessed August 1, 2009.

20. Huber W. Historical remarks on Martin Kirschner and the development of the Kirschner (K)-wire. Indian J Plast Surg. 2008;41:89-92.

21. Jacobs SN, Keep VR. Intravenous regional analgesia using a new local anesthetic agent, prilocaine. Med J Aust. 1965;2(23):956-957.

22. Kaplan D. Unna's boot. $N$ C Med J. 1989;50:103.

23. Kennedy BR, Duthie AM, Parbrook GD, Carr TL. Intravenous regional analgesia: an appraisal. Br Med J. 1965;1:954-957.

24. Kirkup J. The Evolution of Surgical Instruments: An Illustrated History from Ancient Times to the Twentieth Century. Novato, CA: Norman Publishing; 2006.

25. Kirkup J. Thomas' splint. J Med Biogr. 2008;16:104.

26. Kirschner M. Ueber Nagelextension. Beitr Klin Chir. 1909;64:266.

27. Kirschner M. Ein durch die Trendelenburgsche Operation geheilter Fall von Embolie der Art. pulmonalis. Arch Klin Chir. 1924;133:312.

28. Kirschner M. Verbesserung der Drahtextension. Arch Klin Chir. 1927;148:650-658.

29. Kucklick T, ed. The Medical Device $R \& D$ Handbook. Boca Raton, FL: CRC Press; 2005.
30. Martin HA. Rubber Bandage: Reproduced in The Medical Times and Register. Ann Arbor, MI: University of Michigan Library; 2009.

31. McGreevy PS. Amos Barber, Charles Penrose, and the war on Powder River. Surg Gynecol Obstet. 1973;136:632-638.

32. Meals CG, Meals RA. A history of surgery in the instrument tray: eponymous tools used in hand surgery. J Hand Surg Am. 2007;32:942-953.

33. Moog FP, Karenberg A, Moll F. The catheter and its use in late antiquity and the early middle ages. $J$ Urol. 2005;174:439441.

34. Mulvaney WP. Some memories of Frederic Eugene Basil Foley. Urology. 1986;27:191-194.

35. O'Connor JL, Bloom DA. William T. Bovie and electrosurgery. Surgery. 1996;119:390-396.

36. Roguin A. Christian Johann Doppler: the man behind the effect. Br J Radiol. 2002;75:615-619.

37. Romm S. The persons behind the name: Charles Bingham Penrose. Plast Reconstr Surg. 1982;70:397-399.

38. Romm S. Johann Friedrich August von Esmarch. Plast Reconstr Surg. 1983;71:271-273.

39. Romm S. The person behind the name: Martin Kirschner. Plast Reconstr Surg. 1983;72:104-107.

40. Romm S. Fritz Steinmann and the pin that bears his name. Plast Reconstr Surg. 1984;74:306-310.

41. Shapleigh J. Obituary: Dr. Henry A. Martin. Boston Med Surg J. 1885;112:47-48.

42. Speert H. Friedrich Trendelenburg and the Trendelenburg position. Surg Gynecol Obstet. 1957;105:114-119.

43. Steinmann F. Eine neue Extensionsmethode in der Frakturbehandlung. Cor B1 Schweiz Aerate. 1908;38:3.

44. Steinmann F. Nail extension for fractures. $\mathrm{Br}$ Med $\mathrm{J}$. 1912;2:1534-1537.

45. Stryker: History. Available at: http://www.stryker.com/en-us/cor porate/AboutUs/History/index.htm. Accessed December 2, 2009.

46. Trendelenburg F. Ueber die operative Behandlung der Embolie der Lungenarterie. Langebecks Arch Chir. 1908;86:686.

47. Turco SJ, King R. Sterile Dosage Forms: Their Preparation and Clinical Application. Philadelphia, PA: Lippincott Williams \& Wilkins; 1994.

48. Unna P. Die Histopathologie der Hautkrankheiten Berlin, Germany: A. Hirschwald; 1894.

49. van Zundert A, Goerig M. August Bier 1861-1949: a tribute to a great surgeon who contributed much to development of modern anesthesia on the 50th anniversary of his death. Reg Anesth Pain Med. 2000;25:26-33.

50. van Zundert A, Helmstadter A, Goerig M, Mortier E. Centennial of intravenous regional anesthesia: Bier's block (1908-2008). Reg Anesth Pain Med. 2008;33:483-489.

51. Voorhees JR, Cohen-Gadol AA, Laws ER, Spencer DD. Battling blood loss in neurosurgery: Harvey Cushing's embrace of electrosurgery. J Neurosurg. 2005;102:745-752.

52. White DN. Johann Christian Doppler and his effect: a brief history. Ultrasound Med Biol. 1982;8:583-591.

53. Who Named It? Homer H. Stryker. Available at: www.who namedit.com/doctor.cfm/2401.html. Accessed August 1, 2009.

54. Who Named It? Hugh Owen Thomas. Available at: www.who namedit.com/doctor.cfm/2947.html. Accessed August 1, 2009.

55. Who Named It? Paul Gerson Unna. Available at: www.who namedit.com/doctor.cfm/1698.html. Accessed August 1, 2009.

56. Wilson J, Fiske J, eds. Appleton's Cyclopaedia of American Biography. New York, NY: D. Appleton; 2006; No. 4.

57. Zorgniotti AW. Frederic EB. Foley: early development of balloon catheter. Urology. 1973;1:75-80. 